\title{
Possibilities for Personnel Development in the Mining and Quarrying sector in Bulgaria
}

\author{
Mariana Petrova ${ }^{1, *}$, Milena Tepavicharova ${ }^{2}$, and Lyudmila Dikova ${ }^{2}$ \\ ${ }^{1}$ St. Cyril and St. Methodius University of Veliko Tarnovo, Bulgaria \\ ${ }^{2}$ Higher School of Security and Economics, Plovdiv, Bulgaria
}

\begin{abstract}
In today's high tech global economy the need of competent and highly qualified workforce becomes focal point in the research of academics, practitioners and business alike. The development of professional skills and competencies correlates with the processes of performance, evaluation and career development of the human capital. A lot of businesses are looking for innovative ways to improve efficiency and maintain competitive advantage in order to survive. The development of professional competencies is more frequently linked with the processes of performance, evaluation and career development of the human capital. The formation of such competencies requires consistent actions to improve particular knowledge, skills and abilities. The analysis of the professional competences of the human capital in the mining and quarrying sector in Bulgaria reveals a number of opportunities for their effective use and management. The purpose of this article is to outline the main tactics for developing professional competences of the human capital in the mining and quarrying sector analysing the predispositions of young professionals to work in this sector.
\end{abstract}

\section{Introduction}

In today's high tech global economy the need of competent and highly qualified workforce becomes focal point in the research of academics, practitioners and business alike. The development of professional competencies is more frequently linked with the processes of performance, evaluation and career development of the human capital. The formation of such competencies requires consistent actions to improve particular knowledge, skills and abilities. A lot of businesses are looking for innovative ways to improve efficiency and maintain competitive advantage in order to survive $[1,2,3]$. This requires the development of various techniques for improving their business competitiveness [4,5]. The development of professional competencies is more frequently linked with the processes of performance, evaluation and career development of the human capital. Their formation requires consistent actions to improve particular knowledge, skills and abilities. The analysis of the status and trends in the professional competences of the human capital in the mining and quarrying sector in Bulgaria and to present opportunities for efficient training of the workforce, ensuring optimal use of the labor potential of workers in the the mining and

\footnotetext{
*Corresponding author: $\underline{\text { m.petrova@.ts.uni-vt.bg }}$
} 
quarrying sector in Bulgaria. The purpose of this article is to outline the main tactics for developing professional competences of the human capital in the mining and quarrying sector analysing the predispositions of young professionals to work in this sector.

\section{Materials and methods}

According to Eurostat in 2014 there were 19 thousand enterprises operating with mining and quarrying in the EU-28 [6]. They employed 567 thousand people ( $0.4 \%$ of all persons employed in thenon-financial business economy) and generated value added of 64.9 billion EUR (1.0\% of the non-financial business economy total)[6]. The relative importance of the mining and quarrying sector across the EU Member States tends to be highest among the countries specialized in the extraction of fossil fuels: these figures were closely linked to the geological distribution of fossil fuel deposits which were scarce or non-existent in many of the Member States for example the highest ratio in mining of coal and lignite is in Bulgaria while Denmark is the most specialized country in the deriving of crude petroleum and natural gas. [6]

Analysis from Eurostat declares that among the EU Member States, the relative importance of SMEs and large enterprises reflects to some extent their specializations as high shares of value added for large enterprises were recorded in countries with relatively high specializations in activities that are characterized by the presence of large enterprises, for example, coal and lignite mining in Bulgaria, or the extraction of crude petroleum and natural gas in Denmark, the Netherlands and the United Kingdom [6]

As ICT (Information and communication technologies) facilitate the communication and connection between people and businesses without regards of their physical geographical location entrepreneurs find new possibilities to improve and develop their businesses. The automation of business processes becames one of the priority areas for the application of ICT in the business: CRM (Customer Relationship Management); ERP (Enterprise Resource Planning); BI (Business Intelligence); ECM (Enterprise Content Management); SCM (Supply Chain Management); HRM (Human Resource Management) [7]. The importance of ICT in the mining and quarrying sector increases both in terms of productivity and innovations.

The study covers the period April-May 2018. It is based on data from questionnaires specially designed for the purpose of the analysis and secondary data from Eurostat. We applied interviews to clarify the data and information $(\mathrm{N}=23)$. The respondents of the questionnaires $(\mathrm{N}=172)$ are students and recent graduates from bachelors and masters degrees in relevant fields (Plovdiv University "Paisii Hilendarsky"- faculty of Chemistry and faculty of Physics, the University of Mining and Geology "St. Ivan Rilski"). The statistical analysis was done with the SPSS computer software. The qualitative analysis of data was done with the Atlas computer software. We used descriptive statistics, Pearson chi-square test and and Cramer's $\mathrm{V}$ in order to outline any emerging associations in the data. The items in the questionnaire covered the perceptions of the young professionals towards the mining and quarrying sector in Bulgaria and abroad as well as their selfreported readiness to work in this sector in Bulgaria or abroad. The results from the Pearson chi-square test indicate a high degree of association between the place of residence and the readiness to work in the sector in Bulgaria (Chi-square 126,7, Cramer'sV, 330) - the residence from the smaller cities are more prone to this work in Bulgaria that those from the largest cities (Sofia and Plovdiv). The other items such as level of education, age, level of income show no statistically significant association. The qualitative data analysis suggests low interest from the part of young specialists in the mining and quarrying sector in Bulgaria. The main reasons are:

- Fear of unhealthy work conditions. 
- Poor salaries,

- The need to relocate to smaller towns or cities

In the public mind the work in the mining and quarrying sector is related to poor and unsafe work conditions and health threats. Even young specialists with sufficient knowledge of the technical advancements in the sector are wary of working on the site of the plants.

Most of the young specialists consider the wages in the mining and quarrying sector in Bulgaria as lower in comparison to other industrial sectors in Bulgaria and to the mining and quarrying sector in other European countries such as the United Kingdom, Germany etc. As a result many young people who are reluctant to work in this sector in Bulgaria are ready to work in the mining industry abroad for better salaries. The respondents have reported greater expectations for better and healthier working conditions abroad than in Bulgaria (such as better equipment, additional health packages, possibilities for further trainings etc.)

The potential of increasing human capital in the mining and quarrying industry in Bulgaria is related to two main strategies that may be adopted separately or as complementary practices. The first one consists in deliberate extensive effort from the part of the enterprises in the sector to improve the image of the the mining and quarrying sector in the public eye and especially among young qualified specialists. With a special focus on safe and healthy work conditions and the possibilities to grow within their companies. The contacts with the young specialists should start in the universities where the business can meet the potential workforce and advertise the sector as well as early choose best candidates and offer them possibilities for trainings and internships. As from the part of the universities we consider that formal educational practices should address the fulfillment of the social needs of students $[8,9]$ and focus on building competences $[8,10]$ thus the cooperation between the academic bodies and the business could be a valuable tool that helps students transition into professional life.

The second strategy is related to the growing importance of lifelong learning and the inhouse formation of qualified and specialized personnel. The enterprises in the mining and quarrying industry often have a sufficient local pool of workers who lack skills and qualifications but who have their life settled in the location of the plant. The enterprises have the possibility to organize in-house courses for qualification of its workers or partnerships with universities and education institutions where they can send selected workers to increase their qualification. Although there is always the danger of incorrect behavior from the part of the worker who can receive better qualification and then leave the sending business organization there are many possibilities for special work contracts regarding such opportunities.

\section{Results and discussion}

Constant improvement of qualifications and innovative educational practices are a must in today's fast-developing society where new technologies shape the existing spheres of production and services [11]. Lifelong learning is recognized by the OECD as a key goal for education and training, as the progress in technology and international economic integration is rapidly changing the economic landscape and putting an ever greater premium on the need to innovate, improve productivity and to adjust to structural changes painlessly. Furthermore with the increasing importance of a knowledge-based economy the threshold of skills demanded by the employers is being constantly raised, completed by the need for continuous renewal and updating of skills, which is essential for structural adjustment, productivity growth, innovation and effective reallocation of human resources. 


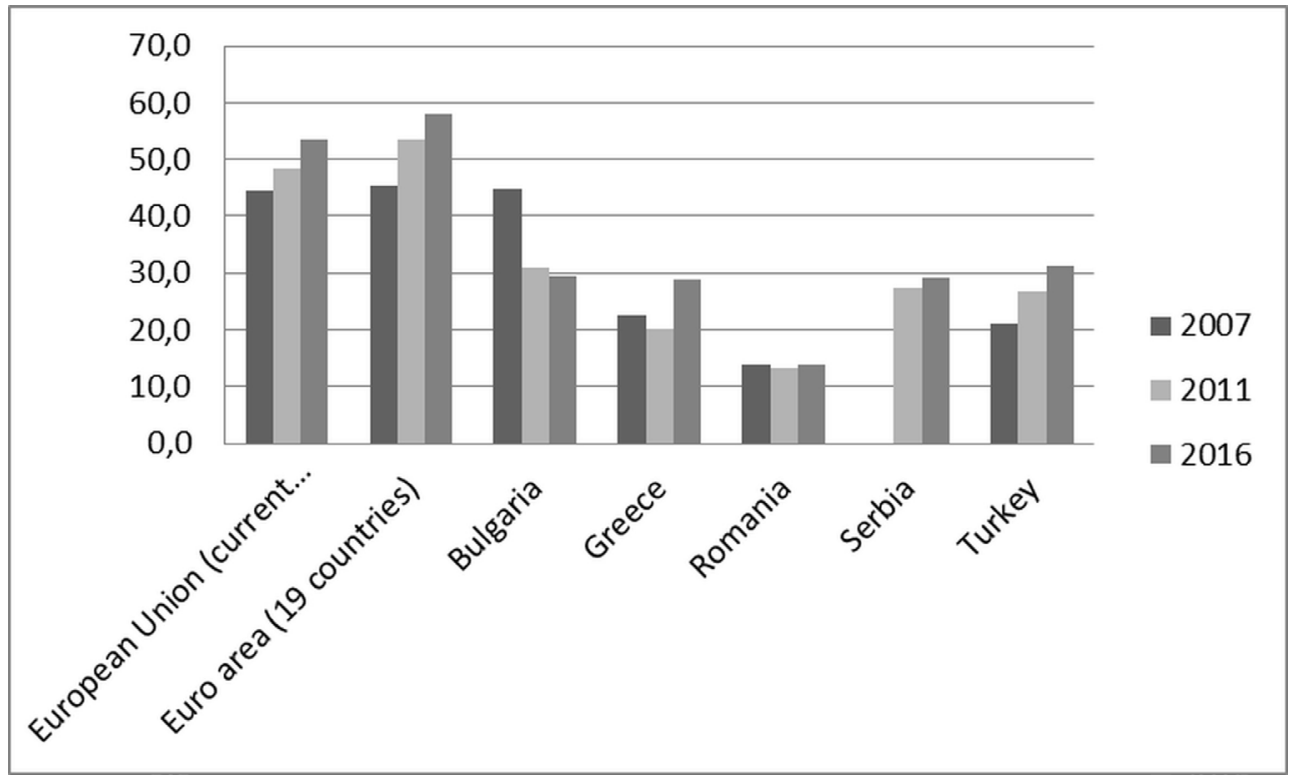

Fig.1. Participation rate in education and training 25 to 34 years (formal and non-formal education and training).

Table 1. Upper secondary education attainment (levels 3 and 4) Population with upper secondary education attainment From 15 to 64 years.

\begin{tabular}{|l|l|l|l|l|l|}
\hline GEO/TIME & $\mathbf{2 0 1 3}$ & $\mathbf{2 0 1 4}$ & $\mathbf{2 0 1 5}$ & $\mathbf{2 0 1 6}$ & $\mathbf{2 0 1 7}$ \\
\hline $\begin{array}{l}\text { European Union (current } \\
\text { composition) }\end{array}$ & 27.9 & 27.5 & 26.9 & 26.5 & 26.0 \\
\hline European Union (15 countries) & 30.2 & 29.6 & 29.0 & 28.6 & 28.1 \\
\hline Bulgaria & 22.1 & 22.6 & 22.2 & 21.9 & 21.4 \\
\hline Czech Republic & 12.9 & 12.4 & 12.4 & 12.4 & 12.1 \\
\hline Greece & 34.5 & 33.1 & 31.5 & 30.0 & 29.3 \\
\hline Croatia & 22.4 & 21.0 & 20.4 & 20.6 & 19.9 \\
\hline Hungary & 22.8 & 22.0 & 21.9 & 21.8 & 21.1 \\
\hline Romania & 28.9 & 31.2 & 29.4 & 28.0 & 27.0 \\
\hline Slovenia & 18.5 & 18.4 & 17.4 & 17.2 & 16.7 \\
\hline Slovakia & 14.7 & 15.2 & 14.6 & 14.3 & 14.8 \\
\hline Montenegro & 21.2 & 20.3 & 19.5 & 19.6 & 19.5 \\
\hline $\begin{array}{l}\text { Former Yugoslav Republic of } \\
\text { Macedonia, the }\end{array}$ & 36.1 & 35.9 & 35.3 & 33.4 & 32.0 \\
\hline Turkey & 67.7 & 67.4 & 66.0 & 64.4 & 63.4 \\
\hline
\end{tabular}

The higher levels of educational attainment (Fig.1. and Table 1.) by the population of a country are considered as a measure of greater human capital. The improvement of the level of individual skills of the workers is associated with higher employment rates and higher payments. Usually the upper secondary and post-secondary non-tertiary educations are a 
sufficient level of education for entering the labour market and starting the wage earning process. The upper secondary qualification is considered a key to sustainable development and has become the norm for young people in OECD countries becoming the minimum qualification for successful participation in the labour market and for integration into society. The lower number of people with upper secondary and post-secondary non-tertiary education in some EU countries that join the labour market is due to the increase in people who decide to continue their education with tertiary education. Such trends are not prominent in Bulgaria where the people prefer to join the labour market at an earlier moment in order to start their wage-earning process.

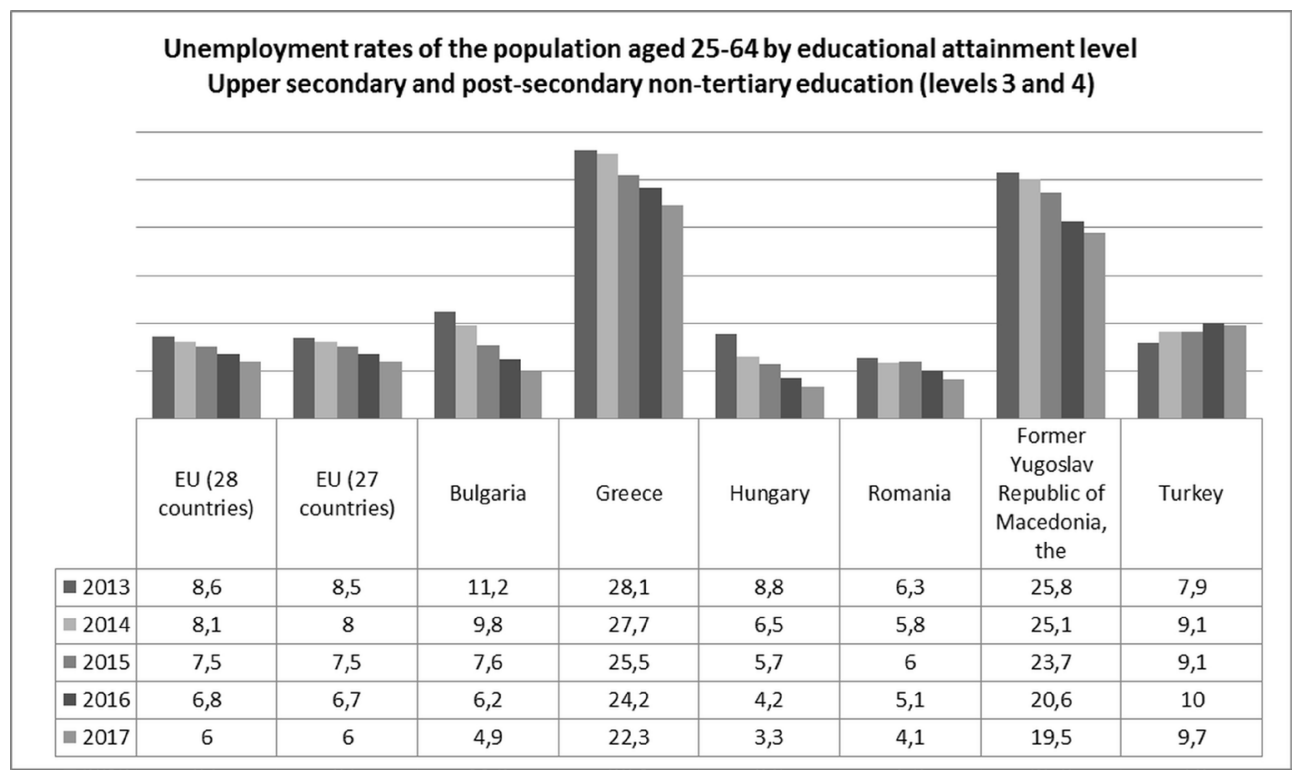

Fig.2. Unemployment 2013-2017.

As the employment rate, by highest level of education attained moderately for the EU average the unemployment rates in Bulgaria and other countries (Fig.2) rise in 2013 and then begin to decrease as since the beginning of the global financial and economic crisis the upper secondary qualification no longer provided sufficient insurance against unemployment and poverty.

Table 2. Population with tertiary education attainment (levels 5-8).

\begin{tabular}{|l|l|l|l|l|}
\hline \multicolumn{1}{|c|}{ GEO/TIME } & $\mathbf{2 0 1 3}$ & $\mathbf{2 0 1 4}$ & $\mathbf{2 0 1 5}$ & $\mathbf{2 0 1 6}$ \\
\hline $\begin{array}{l}\text { European Union } \\
\text { (current composition) }\end{array}$ & $:$ & $:$ & 19530550 & $:$ \\
\hline Bulgaria & 283959 & 283294 & 278953 & 266707 \\
\hline Greece & 659284 & 677429 & 687334 & 704723 \\
\hline Romania Yugoslav & 618157 & 578706 & 541653 & 535218 \\
\hline $\begin{array}{l}\text { Former } \\
\text { Republic of Macedonia, } \\
\text { the }\end{array}$ & 60572 & 63543 & 63252 \\
\hline
\end{tabular}




\begin{tabular}{|l|l|l|l|l|}
\hline Serbia & 238945 & 242848 & 241054 & 251162 \\
\hline Turkey & 4975690 & 5472521 & 6062886 & 6689185 \\
\hline
\end{tabular}

The varying number of the tertiary education attainment (Table 2.) could be explained with the fact that in a difficult economic situation workers try to achieve a competitive edge by tertiary education and enhance their value at the labour market. Furthermore in that way people delay their entrance into the labour market creating a false situation of hope by postponing the job-seeking process by a couple more years. The process of augmentation of the proportion of people having a tertiary education has started in the EU in the late 1990s. After 2008 the evidence suggests that the crisis has accelerated job polarization based on skills levels.

\section{Conclusion}

In regards of the mining and quarrying sector in Bulgaria both businesses and young specialists are oriented toward specialization, high qualifications and development of skills and competences as a way of ensuring competitive edge in the fast developing economy. As young specialist concentrate on formal and non-formal education practices the business should focus on academic cooperation with leading education institutions and the possibilities for lifelong learning practices for their workforce. Lifelong learning is a key resource not only for the employment situation within the countries labor market but also a key factor for the development of human capital and the possibilities for creating competitive and innovative products. We consider that the development of human capital would lead to higher labor productivity in the mining and quarrying sector and ensure a greater value added.

\section{References}

1. O. Sushchenko, I. Trunina, Actual Problems of Economics, 177(3), 191-198 (2016)

2. I. Trunina, O. Sushchenko, Research of competitive advantages of business entities under the conditions of globalization (Modern Electrical and Energy Systems (MEES), Kremenchuk, 2017)

3. M. Petrova, M. Tepavicharova, L. Boykova, Bulletin of Ablai Khan KazUIRandWL, 1:27, 79-85 (2017)

4. O. Sushchenko, M. Petrova, Internet Marketing as a Tool of Tourism Enterprise Strategic Management (National University of Economics, Harkov, 2017)

5. M.S. Sushchenko, Investigation of the method of hiding data in vector images resistant to affine transformations (National University of Economics, Kharkiv, 2016)

6. Mining and quarrying statistics (NACE-Eurostat, Brussel, 2017)

7. M. Petrova, N. Minchev, Y. Dyachenko, Balkan and Near Eastern Studies in Social Sciences, 2:02, 69-75 (2016)

8. F. Boykova, Communicative competency - practices in the education in Bulgarian language (University Paisii Hilendarski, Plovdiv, 2014)

9. V. Nikolova-Aleksieva, Conflict Management in Teamwork (Union of Scientists in Bulgaria, Plovdiv, 2006)

10. T. Mihova, C. Daylyanova, Public sciences, art and culture, I, 22-24 (2014) 
11. N. Nenkov, G. Dimitrov, Y. Dyachenko K. Koeva, Artificial intelligence technologies for personnel learning management systems (IEEE, New York, 2016) 